\title{
3D ADVANCED NUMERICAL MODELLING OF A CATALAN- LAYERED MASONRY VAULT UNREINFORCED AND REINFORCED WITH GLASS-TRM MATERIALS AND SUBJECTED TO VERTICAL SUPPORT MOVEMENTS
}

\author{
E. Bertolesi ${ }^{1}$, G. Milani ${ }^{2}$, J. Adam ${ }^{3}$ and P. Calderón ${ }^{3}$ \\ ${ }^{1}$ Brunel University London, UB8 3PH Uxbridge, UK \\ e-mail: elisa.bertolesi@brunel.ac.uk \\ ${ }^{2}$ Politecnico di Milano, Piazza Leonardo da Vinci 32, 20133 Milan, Italy \\ gabriele.milani@polimi.it \\ ${ }^{3}$ Universitat Politècnica de València, Camino de Vera s/n, 46022 Valencia, Spain \\ \{joadmar, pcaldero\}@upv.es
}

\begin{abstract}
This paper presents the numerical results obtained simulating a 4x4mq masonry vault (unreinforced and reinforced with glass-TRM) tested at the Universitat Politecnica de Valencia (Spain). The vault was built using a traditional Catalan layered-construction technique and its structural behavior was analyzed when subjected to monotonic vertical displacements in one of its supports. The geometry and construction technique of the vault resembled those in a church on the outskirts of Valencia, which collapsed probably due to soil settlements. Indeed, due to their peculiar geometric and mechanical features, these structures are especially prone to damage from support movements produced by ground settlements or earthquakes.

Two advanced $3 D$ numerical models were developed using the commercial software Abaqus to study the vault response with and without the application of an extrados layer of lime based TRM strengthening material. The FE software allowed the adoption of a concrete damage plasticity (CDP) material model which was employed to both masonry support and TRM strengthening material, after a preliminary tuning of the compressive and tensile mechanical properties of the constituent materials.

The outputs obtained with the FE models coupled with the results of the tests, provided valuable information to the scientific community on the available modelling strategies to be used to evaluate the behavior of ancient masonry double-curvature structures pre-damaged by vertical movements of the vault supports and repaired with TRM materials.
\end{abstract}

Keywords: Masonry vaults, Textile Reinforced Mortar (TRM) materials, Vertical Settlements. 


\section{INTRODUCTION}

Textile Reinforced Mortar (TRM) materials represent a valid alternative to Fiber Reinforced Polymers (FRP) [1]-[7] for the reinforcement of ancient structures [8]-[12]. The advantages offered by TRM materials are mainly related to their compatibility with weak ancient substrates and their permeability. In addition, TRM materials offer some of the advantages of FRP composites, as their ease of installation and adaptability to complex geometries. Until now, TRM materials have been studies to characterize their mechanical properties which in turn have helped define guidelines and guide professionals during their design [10]. One of the most important features of this strengthening material, is represented by the mortar matrix, which is generally characterized by a low tensile strength. The adoption of TRM materials has been encouraged in the case of ancient masonries by leveraging their high compatibility and reversibility with respect to ancient supports. An obvious development therefore was the promotion of lime matrices instead of cementitious ones. Unfortunately, the adoption of low tensile strength matrices decreases the global performance of the strengthening solutions themselves which thus needed to be engineered by mixing them with reinforcing fibers. Unlike FRPs, engineered TRM materials usually fail due to slippage phenomena between the reinforcing textile and the mortar matrix [8][10].

Several research groups focused on this aspect, while few research works were developed to study their actual applicability to full-scale structures [13]-[16]. This aspect is particularly important when the support on which the reinforcement is applied is a weak material characterized by negligible tensile strength as in the case of old masonries. In fact, the suitability of a reinforcing solution needs to be evaluated taking into account possible adverse failure mechanisms that the reinforcing material could trigger. Several researches highlighted this aspect especially on isolated masonry panels subjected to diagonal compression or arches reinforced with different strengthening solutions [15]. Furthermore, advanced computational models and analytical approaches were developed mainly on a local scale to study the bonding performance of TRM materials, completely disregarding the effects these reinforcement solutions have on full-scale structures [17]-[22]. One of the first examples of a comprehensive study on the adoption of TRM materials is represented by [23][24]. This work shows the positive and negative effects of TRM solutions when applied on full-scale structures. The results obtained by the lab investigation were used in the present work to propose a 3D macromodelling strategy to study the structural response of masonry layered vaults. The models were used to deduce important outcomes on the limitations of TRM strengthening materials.

\section{EXPERIMENTAL CAMPAIGN}

This section is devoted to the discussion of the results obtained by a unique laboratory investigation developed at the Universitat Politecnica de Valencia (Valencia, Spain) on one masonry timbrel vault damaged by vertical settlements and repaired by an extrados radial TRM strengthening configuration. The vault had a square $4 \times 4 \mathrm{mq}$ shape and it was constructed on four concrete supports interconnected by a steel bracing frame. The vault was subjected to different settlements during two laboratory tests: a downward settlement up to $40 \mathrm{~mm}$ was applied to one support (I test), then the vault was repaired by applying a extrados layer of TRM materials and it was re-tested by imposing a total downward settlement up to $120 \mathrm{~mm}$ (II test). The vault geometry and displacement history are depicted in Figure 1 -a and -b respectively. The reader is referred to [23][24] for further details. The strengthening material was composed of a 10-15 mm thick fibre reinforced natural hydraulic lime and eco-pozzolan based mortar reinforced with a glass textile. 


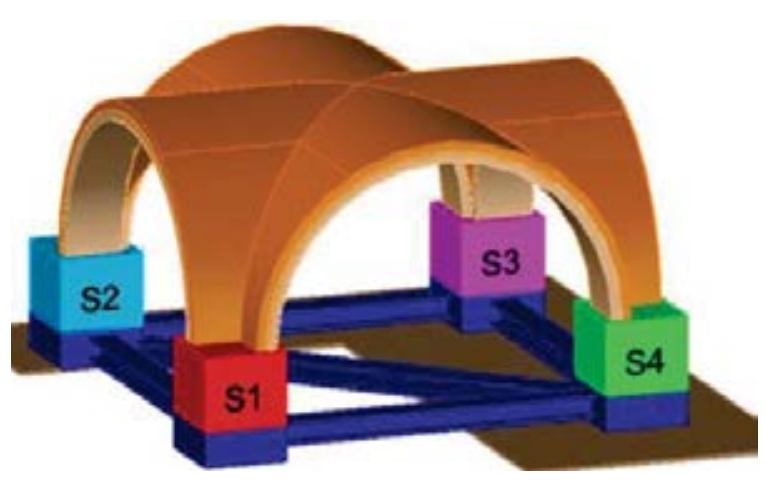

$-\mathrm{a}$

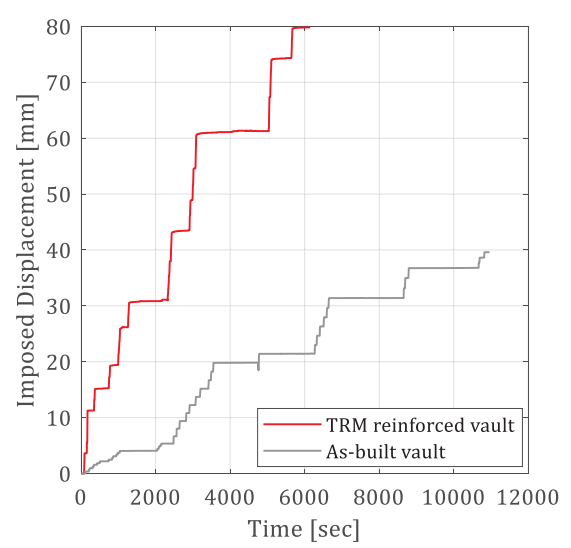

$-b$

Figure 1: Geometry of the tested vault (-a) and downward settlement applied to one support (-b).

The vault was rested on four supports: the vertical settlement was applied in S1, the opposite counterpart (S3) was completely fixed while, the remaining two supports (S2 and S4) were only allowed to slide horizontally. The vertical downward displacement was applied by means of two mechanical jacks placed below S1. Similarly to S2 and S4, S1 was designed to slide horizontally. The vault behavior was monitored by means of different sensors, namely: Linear Variable Displacement Transducers and Fiber Optic sensors. In particular, Figure 2 -a and $-b$ depicts the results obtained at the end of the experimental investigation in terms of reaction force vs. imposed settlement curves and damage patterns, respectively (test II).

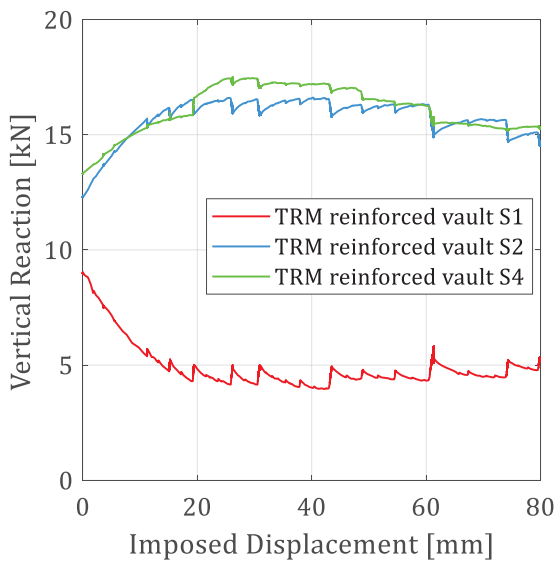

$-\mathrm{a}$

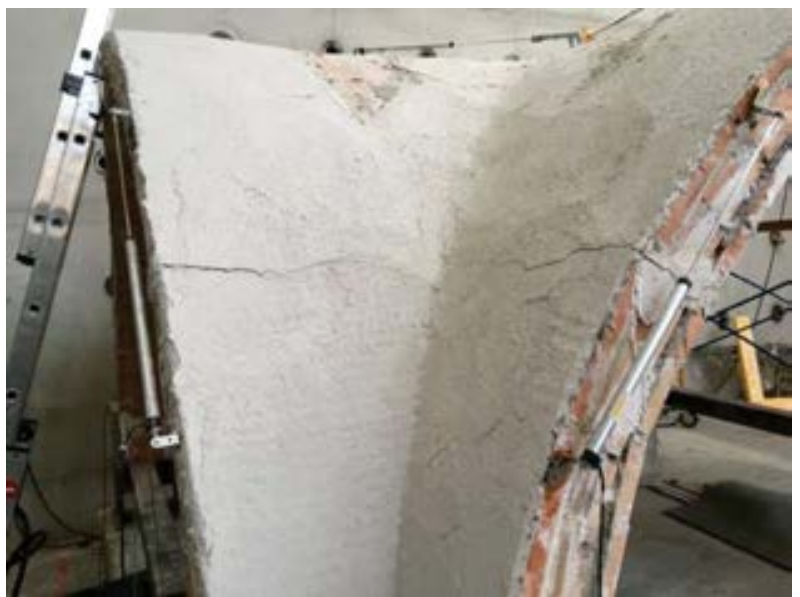

$-\mathrm{b}$

Figure 2: Experimental reaction force vs vertical settlement curves (-a) and crack patterns at the end of the investigation (-b).

As visible in Figure 2, the vault reinforced with TRM composites, experienced the formation of various cracks, namely an extrados diagonal crack connecting the two lateral supports S2-S4 and traditional hinged mechanisms in the lateral arches (S1-S2 and S1-S4). The application of TRM materials was able to restore the continuity of the masonry structure severely damaged by previous settlements. Also, the damage patterns showed that for extrados 
reinforcements, the strengthening material experienced some mortar cracking without textile slippages or tensile failures.

\section{NUMERICAL MODELLING}

This section is provided to discuss the assumptions made during the FE analysis. The following hypotheses lie at the basis of the models developed in Abaqus:

- The masonry support was modeled as a homogeneous material. This simplification, not normally available for traditional masonry, is adopted here due to the peculiar characteristics of layered masonry structures. The layered support was in fact composed of a stacked sequence of tiles and joints arranged along two perpendicular directions.

- The longitudinal axis of symmetry was considered to reduce the computational cost of the simulations. In fact, the masonry structure should have behaved symmetrically during the entire experimental campaign. During the laboratory investigations some torsional effects were observed, due to geometric and material heterogeneity. These effects do not invalidate the initial hypothesis since they could hardly be considered in standard simulations.

- The vault behavior during the two-stage lab campaign was decoupled allowing the adoption of two models: one considering the unreinforced masonry and the other considering the TRM strengthening material applied on an undamaged support. This assumption holds considering that the masonry support was subjected to repointing and injections before applying the TRM material. Also, the reaction force-settlement curves showed that the initial stiffness of the vault was completely restored after the strengthening interventions.

\subsection{Unreinforced and TRM Reinforced structure}

The vault behavior was modeled using a 3D macro-modelling strategy using 4-noded shell elements representing the masonry support and strengthening material. The final models are depicted in Figure $3-a$ and $-b$, respectively considering the unreinforced and TRM reinforced vaults.

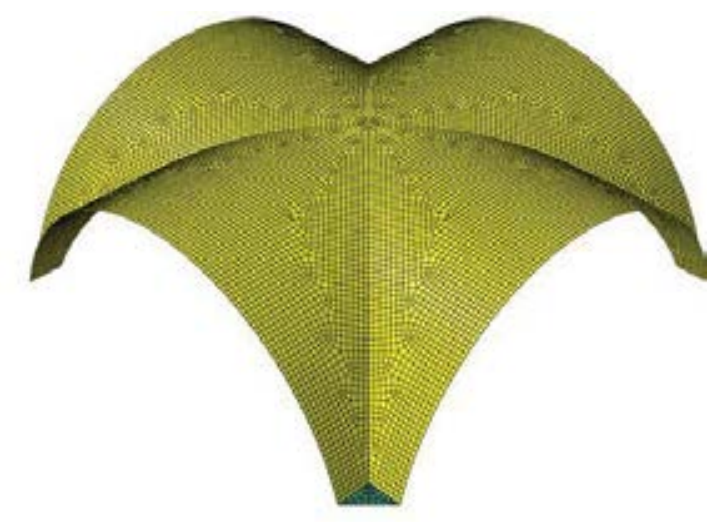

$-\mathrm{a}$

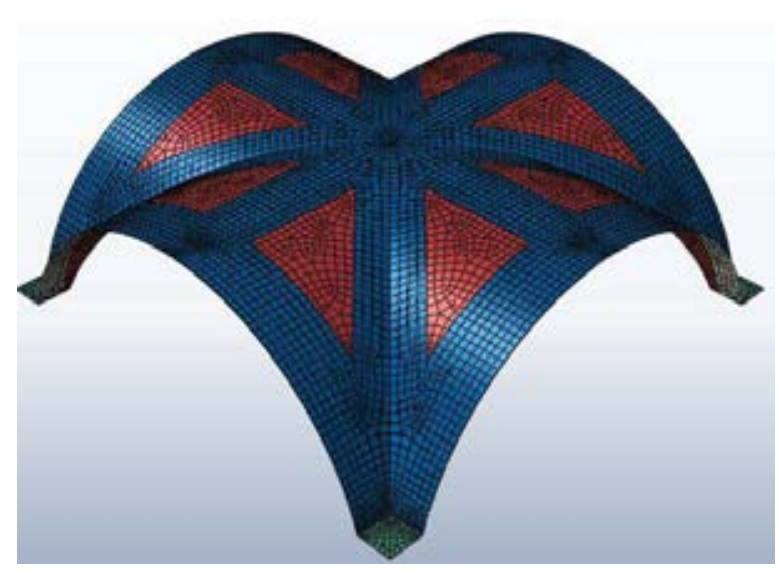

$-\mathrm{b}$

Figure 3: 3D models of the timbrel vault: unreinforced structure (-a) and TRM reinforced structure (-b). 
In details, the thickness of the masonry supports was considered equal to $70.5 \mathrm{~mm}$ for the vault and $159.5 \mathrm{~mm}$ in the lateral arches while, the TRM thickness was set to $10 \mathrm{~mm}$. In order to realistically study the effect of vertical settlements, the masonry support and TRM materials were simulated using a Concrete Damage Plasticity (CDP) model available in Abaqus. The elastic modulus of the masonry support was set to $1700 \mathrm{MPa}$, with tensile and compressive strengths equal to $0.23 \mathrm{MPa}$ and $10 \mathrm{MPa}$, respectively. The TRM mechanical properties were deduced according to the data provided by the manufacturer when available. In details, the authors assumed an elastic modulus equal to $3179 \mathrm{MPa}$ and compressive strength equal to $17 \mathrm{MPa}$.

\section{NUMERICAL RESULTS}

\subsection{Unreinforced Structure}

This section discusses the results obtained using the Abaqus FE model and considering only the unreinforced vault. For the sake of brevity, the damage maps are briefly discussed in this section (see Figure 4). Figure 4-a and -b depicts the tensile damage maps (red stands for $90 \%$ damage whereas blue stands for $0 \%$ of damage) obtained at the end of the simulation and at the end of the first lab test, respectively.

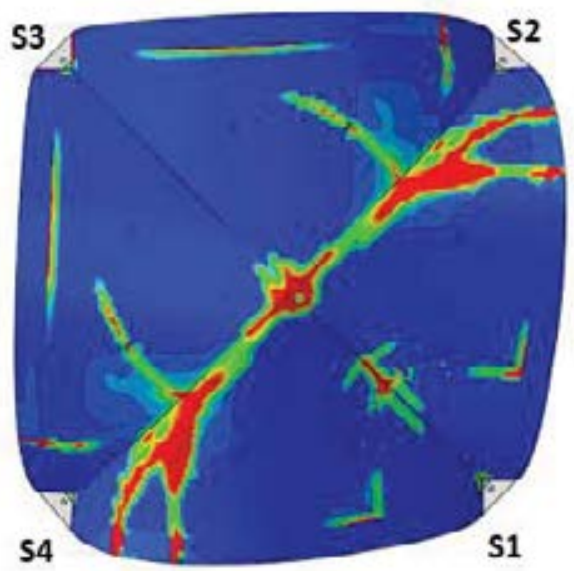

$-\mathrm{a}$

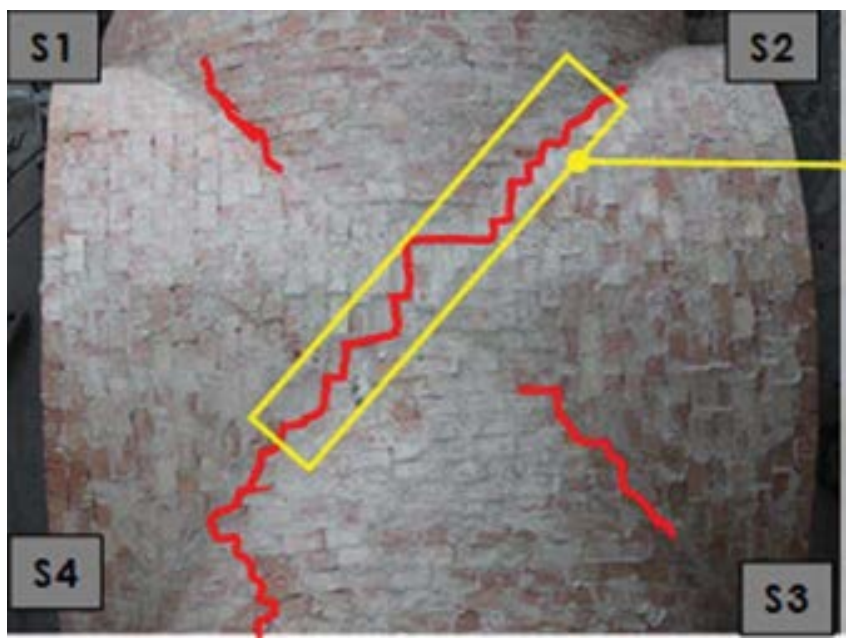

$-\mathrm{b}$

Figure 4: Tensile damage maps at the vault extrados: FE modelling (-a) and lab test (-b).

As visible comparing Figure 4-a and -b, the model was able to describe accurately the development of the failure mechanism found experimentally. The most important damage was observed along the diagonal connecting supports S2-S4 and along the lateral arches S1-S2 and S1-S4.

\subsection{TRM Reinforced Structure}

The TRM reinforced vault was modelled using the same approach discussed in the previous sections. In this section the most important numerical results are presented and discussed with respect to the experimental outcomes. Figure 5 -a depicts the numerical tensile damage maps plotted at the vault extrados at the end of the simulation while, Figure 5-b proposes a 
comparison between the reaction forces-settlement curves obtained experimentally and numerically.

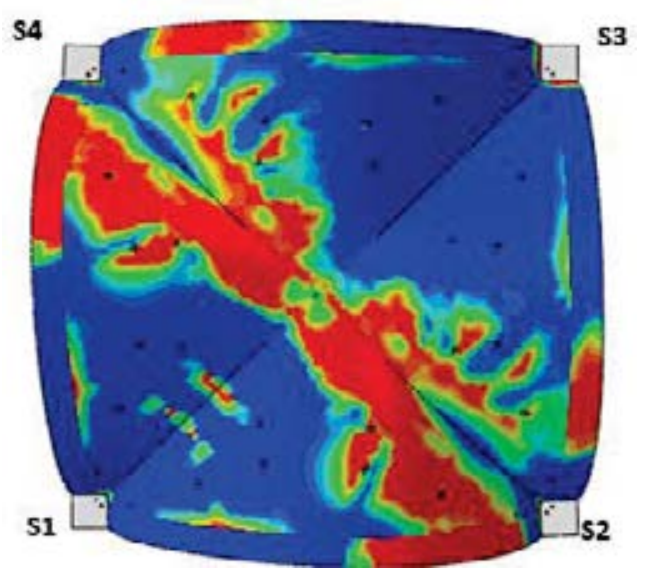

$-a$

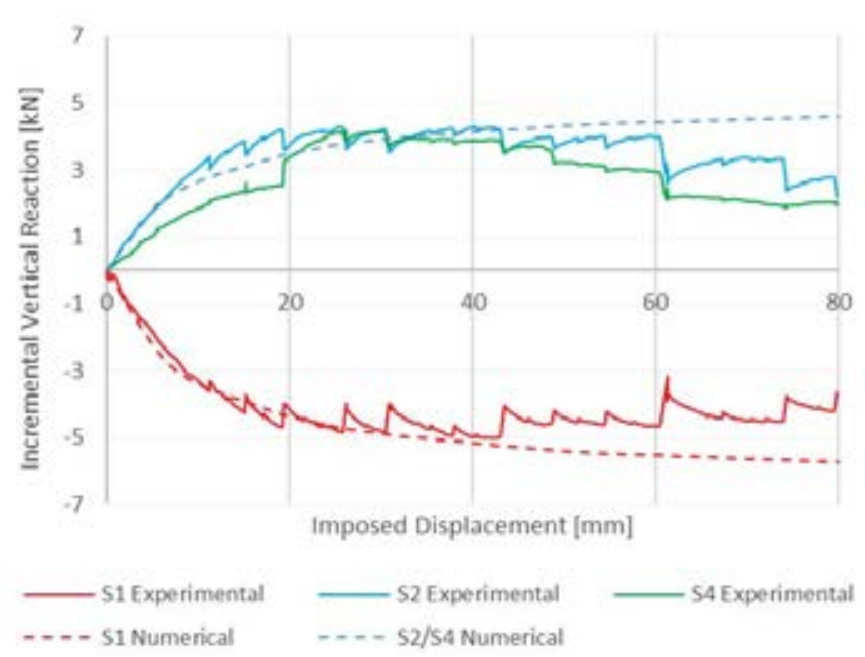

$-b$

Figure 5: Experimental reaction force vs vertical settlement curves (-a) and crack patterns at the end of the investigation (-b).

As visible in Figure 5-b the model is able to capture the global structural response of the vault in terms of initial stiffness, peak reaction load and post peak behavior. Similarly, the adopted FE approach successfully described the failure mechanism which was characterized by spreading tensile damages on the masonry substrate in correspondence of the S2-S4 diagonal and mostly in the lateral arches S1-S4 and S1-S2.

\section{CONCLUSIONS}

The article discusses a series of numerical simulations developed using the commercial software Abaqus to study the structural response of masonry vaults damaged by vertical settlements. Based on the results obtained, the following conclusions could be drawn:

- A macro-modelling approach was successfully adopted to study the behavior of unreinforced and TRM reinforced masonry vaults.

- The model, although simplified, was able to capture the global structural response of the structure and the development of the failure mechanism.

- The TRM strengthening was successfully applied to restore the continuity of the vault also, extending the displacement capacity of the structure. Conversely, increasing the displacement capacity increases spreading the damages on the masonry support before failure of the strengthening material. This is particularly evident comparing Figure 4-a with Figure 5-a.

- This latter finding is particularly interesting as it suggests using the TRM materials cautiously especially for historic structures where the focus is on preserving the structural integrity. The results suggest to couple FE models to monitoring strategies in order to verify the behavior of the structure and implement soil improvement interventions before reaching a critical state of the masonry. 


\section{REFERENCES}

[1] T. Rotunno, M. Fagone, E. Bertolesi, E. Grande, G. Milani, Single lap shear tests of masonry curved pillars externally strengthened by CFRP strips, Composite Structures, 200, 434-448, 2018.

[2] E. Bertolesi, G. Milani, M. Fagone, T. Rotunno, E. Grande, Micro-mechanical FE numerical model for masonry curved pillars reinforced with FRP strips subjected to single lap shear tests, Composite Structures, 201, 916-931, 2018.

[3] G. Milani, M. Fagone, T. Rotunno, E. Grande, E. Bertolesi, Development of an interface numerical model for C-FRPs applied on flat and curved masonry pillars, Composite Structures, 241, 2020.

[4] E. Grande, M. Fagone, T. Rotunno, E. Bertolesi, G. Milani, Modelling of the bond behaviour of curved masonry specimens strengthened by CFRP with anchor spikes, Composites Part B: Engineering, 171, 235-245, 2019.

[5] T. Rotunno, M. Fagone, E. Bertolesi, E. Grande, G. Milani, Curved masonry pillars reinforced with anchored CFRP sheets: An experimental analysis, Composites Part B: Engineering, 174, 2019.

[6] M. Fagone, T. Rotunno, E. Grande, E. Bertolesi, G. Milani, The influence of the joint thickness on the adhesion between CFRP reinforcements and masonry arches, Procedia Structural Integrity, 11, 258-265, 2018.

[7] E. Grande, M. Fagone, T. Rotunno, E. Bertolesi, G. Milani, Coupled interface-based modelling approach for the numerical analysis of curved masonry specimens strengthened by CFRP, Composite Structures, 200, 498-506, 2018.

[8] L. Alexandros, S.K. Thanasis, C. Triantafillou, State-of-the-art on strengthening of masonry structures with textile reinforced mortar (TRM), Constr Build Mater, 188, 12211233, 2018.

[9] E. Bertolesi, M. Buitrago, E. Giordano, P. A. Calderón, J. J. Moragues, F. Clementi, J. M. Adam, Effectiveness of textile reinforced mortar (TRM) materials in preventing seismic-induced damage in a U-shaped masonry structure submitted to pseudo-dynamic excitations, Constr Build Mater, 248, 2020.

[10] E. Bertolesi, F. G. Carozzi, G. Milani, C. Poggi, Numerical modeling of Fabric Reinforce Cementitious Matrix composites (FRCM) in tension, Constr Build Mater, 70, 531548, 2014.

[11] F. G. Carozzi, C. Poggi, E. Bertolesi, G. Milani, Ancient masonry arches and vaults strengthened with TRM, SRG and FRP composites: Experimental evaluation, Composite Structures, 187, 466-480, 2018.

[12] E. Bertolesi, G. Milani, F. G. Carozzi, C. Poggi, Ancient masonry arches and vaults strengthened with TRM, SRG and FRP composites: Numerical analyses, Composite Structures, 187, 385-402, 2018.

[13] B. Torres, S. Ivorra, F. J. Baeza, L. E. B. Varona, Textile reinforced mortars (TRM) for repairing and retrofitting masonry walls subjected to in-plane cyclic loads. An experimental approach, Engineering Structures, 231, 2021.

[14] B. Torres, F.B. Varona, F.J. Baeza, D. Bru, S. Ivorra, Study on retrofitted masonry elements under shear using digital image correlation, Sensors, 20, 2020. 
[15] X. Wang, C.C. Lam, V. PanIu, Comparison of different types of TRM composites for strengthening masonry panels, Constr Build Mater, 219, 184-194, 2019.

[16] F.A. Kariou, S.P. Triantafyllou, D.A. Bournas, L.N. Koutasc, Out-of-plane response of masonry walls strengthened using textile-mortar system, Constr Build Mater, 165, 769781, 2018.

[17] E. Grande, G. Milani, Procedure for the numerical characterization of the local bond behavior of FRCM, Composite Structures, 258, 2021.

[18] E. Grande, M. Imbimbo, S. Marfia, E. Sacco, Numerical simulation of the de-bonding phenomenon of FRCM strengthening systems, Frat Ed Integrita Strutt, 13, 321-333, 2019.

[19] E. Grande, B. Ghiassi, M. Imbimbo, Theoretical and FE models for the study of the bond behavior of FRCM systems, Numer Model Mason Hist Struct, 685-712, 2019.

[20] E. Grande, G. Milani, Interface modeling approach for the study of the bond behavior of FRCM strengthening systems, Compos B Eng, 141, 221-233, 2018.

[21] E. Bertolesi, G. Milani, C. Poggi, Simple holonomic homogenization model for the nonlinear static analysis of in-plane loaded masonry walls strengthened with FRCM composites, Composite Structures, 158, 291-307, 2016.

[22] E. Bertolesi, J. M. Adam, P. Rinaudo, P. A. Calderón, Research and practice on masonry cross vaults - A review, Engineering Structures, 180, 67-88, 2019.

[23] B. Torres, E. Bertolesi, J.J. Moragues, P.A. Calderón, J.M. Adam, Experimental investigation of a full-scale timbrel masonry cross vault subjected to vertical settlement, Constr Build Mater, 221, 421-432, 2019.

[24] E. Bertolesi, B. Torres, J. M. Adam, P. A. Calderón, J. J. Moragues, Effectiveness of Textile Reinforced Mortar (TRM) materials for the repair of full-scale timbrel masonry cross vaults. Engineering Structures, 220, 110978, 2020. 